\title{
Anti-tumor activity of arginine deiminase via arginine deprivation in retinoblastoma
}

\author{
JEONG HUN KIM ${ }^{1}$, JIN HYOUNG KIM², YOUNG SUK YU ${ }^{1}$, \\ DONG HUN KIM ${ }^{3}$, BON-HONG MIN ${ }^{4}$ and KYU-WON KIM ${ }^{2}$
}

\begin{abstract}
${ }^{1}$ Department of Ophthalmology, College of Medicine, Seoul National University, Seoul; ${ }^{2}$ Neuro Vascular Coordination Research Center, College of Pharmacy and Research Institute of Pharmaceutical Sciences, Seoul National University, Seoul 151-742; ${ }^{3}$ Department of Radiology, College of Medicine, Chosun University, Gwangju; ${ }^{4}$ Department of Pharmacology and BK21 program for Medical Sciences, College of Medicine, Korea University, Seoul, Korea
\end{abstract}

Received July 24, 2007; Accepted September 4, 2007

\begin{abstract}
In spite of recent advances in the treatment of retinoblastoma, chemotherapy is still challenging in high-stage intraocular retinoblastoma or metastatic retinoblastoma. Here, we investigated whether arginine deprivation via arginine deiminase (ADI) could be a new anti-tumor therapy in retinoblastoma cells. Expression of argininosuccinate synthetase (ASS) was detected in human retinoblastoma tissues. Even with a high expression of ASS, ADI effectively inhibited the proliferation of retinoblastoma cells and induced retinoblastoma cell death in a dose-dependent manner. These results indicate that arginine deprivation via ADI could be another treatment option for retinoblastoma due to low ASS activity in retinoblastoma cells.
\end{abstract}

\section{Introduction}

Retinoblastoma is the most common intraocular cancer in children (1). Both hereditary and non-hereditary retinoblastomas result from the inactivation of the representative tumor suppressor gene, $R B 1$ (2). Treatment options including enucleation, radiation, chemotherapy and additional local treatments of cryotherapy, laser photocoagulation, and thermotherapy have been successful in saving lives. Usually, patients with unilateral retinoblastoma undergo enucleation, whereas children with bilateral retinoblastoma often undergo anti-cancer therapy to avoid bilateral enucleation and blindness. Recently, chemotherapy combined with local treatments has improved the rate of eye salvage or vision preservation (3-5). A currently used chemotherapy regimen

Correspondence to: Dr Young Suk Yu, Department of Ophthalmology, College of Medicine, Seoul National University, Seoul, 110-744, Korea

E-mail: ysyu@snu.ac.kr

Key words: arginine deiminase, retinoblastoma, arginine deprivation, argininosuccinate synthetase for retinoblastoma is based on carboplatin and etoposide, which originated from another rare childhood solid cancer of the central nervous system (6). However, chemotherapy is still challenging in high-stage intraocular retinoblastoma or metastatic retinoblastoma. For years, alternative chemotherapeutic combinations have not been identified. Moreover, etoposide has been known to increase acute myeloblastic leukemia as a secondary malignancy which is likely due to its topoisomerase II inhibitory effect (7).

Amino acid deprivation therapy has been encouraged in the field of cancer treatment. Amino acid degrading enzymes, such as paraginase and methioninase, have been encouraged as potent anti-tumor agents $(8,9)$. Similarly, arginine is a semi-essential amino acid to be depleted in normal cell metabolism (10) and arginine deiminase (ADI) is an arginine degrading enzyme that catalyzes the hydrolysis of arginine into citrulline and ammonia. We and other research groups showed that arginine deprivation by ADI could be a possible cancer treatment (11-16). Arginine-auxotrophic tumor cells cannot survive in an arginine-deprived condition, but in fact, some cells can live well with ADI, because citrulline could be converted to arginine in 2 steps by using enzymes arginino-succinate synthetase (ASS) and argininosuccinate lyase (ASL) (17). ASS is known as the rate-limiting enzyme in the conversion of citrulline into arginine, so anti-tumor activity of ADI generally depends on the cellular ASS activity and citrulline to arginine recycling (18).

In this study, we investigated whether ADI has anti-tumor activity in retinoblastoma cells. To examine this hypothesis further, we checked the expression of ASS in human retinoblastoma tissues and retinoblastoma cell lines. To evaluate both the anti-tumor activity of ADI and ASS activity in retinoblastoma cells, we compared cell growth and lactate dehydrogenase $(\mathrm{LDH})$ release in ADI-treated cells to that in L-arg deprived cells without ADI treatment.

\section{Materials and methods}

Materials. Recombinant arginine deiminase (rADI) was purified in our laboratory as previously described (15). Briefly, rADI was purified to homogeneity on SDS-PAGE from inclusion bodies accumulated in the cytoplasm of $E$. coli BL21 
(DE3) (Novagen, Madison, WI) transformed with pET32aADI and had a specificity of 50 units/mg protein. One unit of ADI is the amount of enzyme catalyzing $1 \mu$ mole of arginine to citrulline per min at $37^{\circ} \mathrm{C}$ under the assay conditions.

Tissue preparation and immunohistochemistry. All human retinoblastoma tissue samples were obtained with informed consent, institutional review board approval, and in accordance with the tenets of the Declaration of Helsinki. Primarily enucleated eyeballs from patients diagnosed with retinoblastoma were obtained from the Seoul National University Children's Hospital. After nucleation, the eyeballs were fixed by immersion in Carnoy's solution for $2 \mathrm{~h}$ at room temperature. Each specimen was then dehydrated through a series of graded ethanol solutions and embedded in paraffin using standard techniques. Paraffin-embedded eyes were sectioned into $4 \mu \mathrm{m}$ sections, and sections were then mounted on slides coated with $0.5 \%$ Elmer's glue for immunohistochemistry. Immunohistochemistry was performed using an Inno-Genex (San Ramon, CA) immunohistochemistry kit. For ASS immunostaining, anti-ASS monoclonal antibody (BD Biosciences, Bedford, MA) was used at the concentration of 1:200 and TRITCconjugated IgG (1:400, Jackson ImmunoResearch) were used as secondary antibodies.

Cell culture. Human mammary adenocarcinoma (MCF-7) cells were generously donated by Dr Min and the Y79 retinoblastoma cell line was purchased from the American Type Culture Collection (Manassas, VA). Retinoblastoma SNUOTRb1 cells were established from a 3-year old retinoblastoma patient, who was diagnosed with a primary retinoblastoma at Seoul National University Children's Hospital (Korea). MCF-7 cells were maintained in Dulbecco's minimal essential medium (DMEM) (Gibco BRL, Rockville, MD), supplemented with $10 \%$ fetal bovine serum and $1 \%$ penicillin/ streptomycin (Gibco BRL). Retinoblastoma cells were cultured in RPMI-1640 (Gibco BRL) supplemented with $10 \%$ fetal bovine serum and $1 \%$ penicillin/streptomycin in a humidified $5 \% \mathrm{CO}_{2}$ incubator at $37^{\circ} \mathrm{C}$. For LDH assay, L-argfree DMEM medium was a product of Gibco BRL and L-argfree/L-cit medium was supplemented with $1 \mathrm{mM}$ L-citrullin and $1 \mathrm{mM}$ ammonium chloride (Sigma). For experiments in this report, the $\mathrm{L}$-arg-free DMEM medium is designated as ' $\mathrm{L}$ arg-free DMEM medium', and L-arg-free DMEM medium supplemented with $1 \mathrm{mM} \mathrm{L}$-arg is designated as a "control medium'.

Western blot analysis. Western blotting was performed using the standard Western blotting methods. The protein concentration in the cytosolic fraction was measured using a BCA protein assay kit (Pierce, Rockford, IL). For Western blot analysis, anti-ASS monoclonal antibody was used at a concentration of 1:1000 (BD Biosciences), and horseradish peroxidase-conjugated anti-mouse IgG was used at 1:10,000 dilution. To ensure the equal loading of protein in each lane, the blots were stripped and reprobed with an antibody against B-actin.

Reverse transcription-polymerase chain reaction. Total RNA was prepared from cells using TRIzol reagent (Invitrogen,
New Zealand), according to the manufacturer's protocol. RNA was dissolved in diethyl pytocarbonate (DEPC) $-\mathrm{H}_{2} \mathrm{O}$ and first-strand cDNA synthesis was performed using Super Script $^{\mathrm{TM}}$ II Rnase H-reverse transcriptase (Invitrogen) and an oligo-dT primer. The cDNA was subjected to 30 cycles of amplification using the primers; ASS Forward 5'- CCTGAT GGAGTACGCAAAGC-3' and Reverse 5'- ACACCAGCTC AGCAAATTTC-3', ASL Forward 5'-GCTCCGAGCAGAA CTCAACT-3' and Reverse 5'-TTTGCGGACCAGGTAAT AGG-3', GAPDH Forward 5'-AAGGTCATCCCTGAGCT GAA-3' and Reverse 5'-CCCCTCTTCAAGGGGTCTAC-3' at $95^{\circ} \mathrm{C}$ for $1 \mathrm{~min}, 58^{\circ} \mathrm{C}$ for $1 \mathrm{~min}$, and $72^{\circ} \mathrm{C}$ for $1 \mathrm{~min}$. The PCR products were analyzed on $1 \%$ agarose gels stained with ethidium bromide.

Cell proliferation assay. Cells $\left(1 \times 10^{5}\right)$ were seeded in 12-well culture plates, and then treated with various concentrations of ADI $(0.25-5 \mathrm{mU} / \mathrm{ml})$. After 3 days, aliquots of cells were mixed with trypan blue dye $(1: 1)$ and loaded onto a haemocytometer. Total cell number was counted and dead cells were specifically identified as those that had taken up the blue dye. The percentage of dead cells was then calculated as a proportion of the total cell number.

Cell cytotoxicity. This was assessed using the LDH assay kit (Promega, Madison, WI) according to the manufacturer's protocol. Cells $\left(1 \times 10^{4}\right)$ were seeded in a 96 -well plate (Nunc, Roskilde, Denmark) in 10\% FBS DMEM medium or L-argfree medium supplement with L-citrullin and ammonium chloride. After treatment with various concentrations of ADI $(0.25-5 \mathrm{mU} / \mathrm{ml})$ for 3 days, the culture medium was mixed with an equal volume of LDH substrate solution in the dark for $30 \mathrm{~min}$. The reaction was stopped with $1 \mathrm{M}$ acetic acid, and the absorbance was measured at $490 \mathrm{~nm}$.

Statistical analysis. Data are expressed as mean \pm S.D. Comparisons between the controls and treated groups were performed using the Student's t-test. $\mathrm{P}<0.05$ was considered statistically significant.

\section{Results}

Expression of ASS in human retinoblastoma tissues. ASS was immunoreactive in all retinoblastoma tissues of 20 patients, which were randomly selected and examined (Fig. 1). ASSpositive viable cells were widely distributed over the tumor, but were not co-localized with DAPI-positive cells even though these existed around the rosettes.

ASS and ASL are expressed in retinoblastoma cell lines. To evaluate eligibility for arginine deprivation therapy with ADI, the expression levels of ASS was measured in retinoblastoma cell lines by Western blot analysis. Previously, we showed that ASS expression is relatively high in MCF-7 cells (16), and thus we used its levels as a positive control. We found that ASS is expressed at a high level in retinoblastoma cell lines, such as Y79 and SNUOT-Rb1, comparable to the levels seen in MCF-7 (Fig. 2A). We also confirmed ASL expression in retinoblastoma cell lines by RT-PCR (Fig. 2B). The expression level of ASS was high in retinoblastoma cell lines, which 

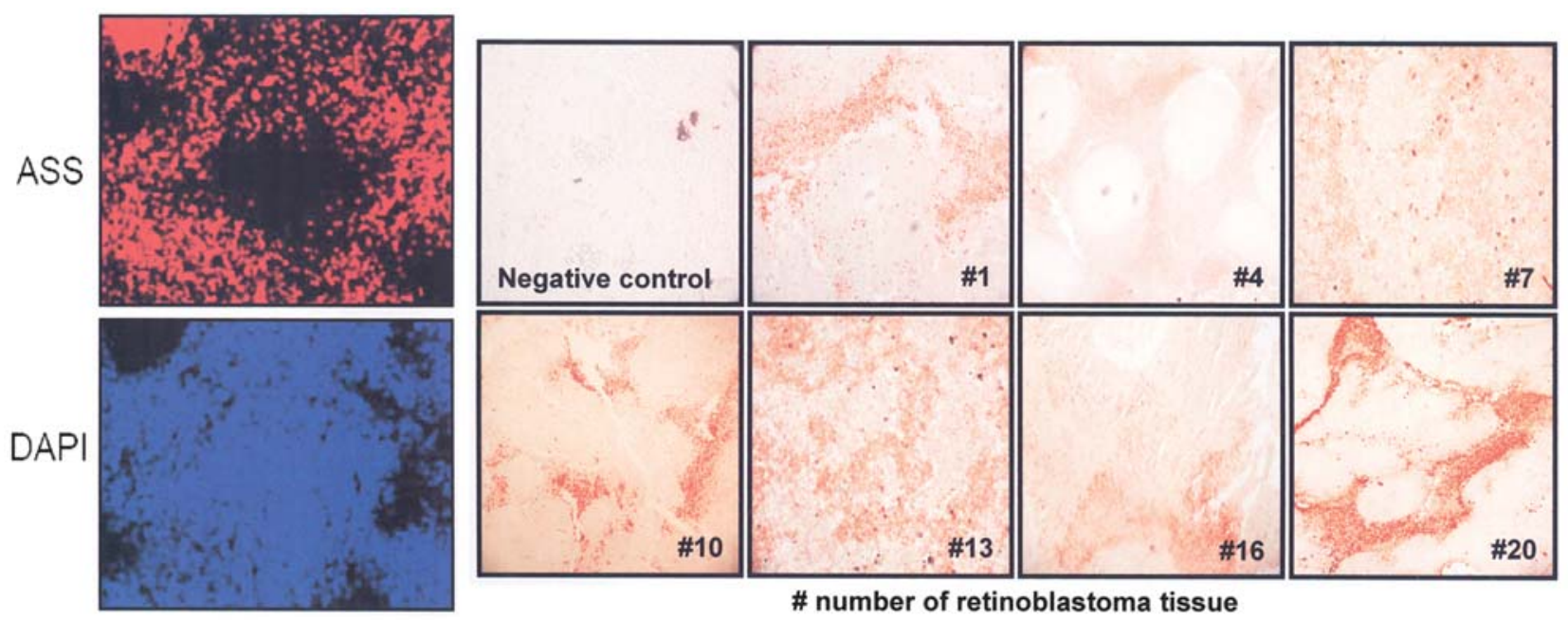

Figure 1. Immunohistochemistry of ASS in human retinoblastoma tumors. Tumor tissues from 20 patients were subjected to immunohistochemistry and analyzed for ASS expression. ${ }^{\#}$, the number of retinoblastoma tissue.
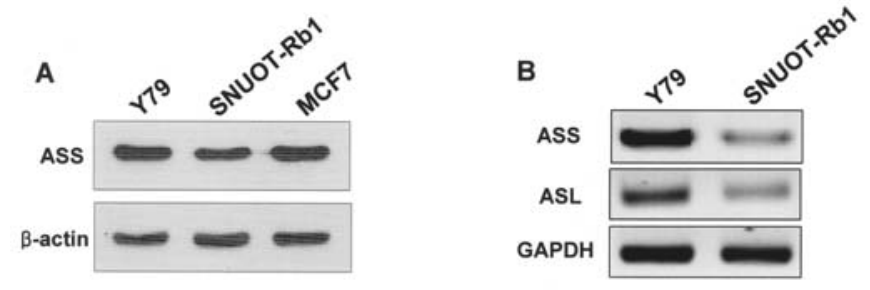

Figure 2. Expression of ASS and ASL in retinoblastoma cell lines (Y79, SNUOT-Rb1) and MCF-7 cells. (A) Protein samples of each cell were resolved on $12 \%$ SDS-PAGE and Western blot analysis was performed using a human anti-ASS monoclonal antibody. MCF-7 cells were used as a positive control. (B) Total RNA was extracted from the cells and then firststrand cDNA was synthesized from $1 \mu \mathrm{g}$ of total RNA by using reverse transcriptase and oligo-dT. Amplification of mRNA of ASS and ASL was carried out as described in Materials and methods.

suggests that arginine deprivation therapy via ADI may not be applicable to retinoblastoma.

ADI inhibits proliferation and induces cell death of retinoblastoma cells. We treated retinoblatoma cells (SNUOT-Rb1, Y79) with ADI (0.25-5 mU/ml) for $72 \mathrm{~h}$ and measured cell growth by the trypan blue exclusion method (Fig. 3A). A significant suppression in cell proliferation was observed in both retinoblastoma cell lines treated with ADI in a dosedependent manner. To test the possibility that ADI treatment may cause cell death, LDH released in culture media was measured. Fig. 3B shows that levels of LDH release is increased by ADI treatment in SNUOT-Rb1 and Y79 cells, while there are no changes in $\mathrm{MCF}-7$ cells.

ASS activity is lacking in retinoblastoma cells. Although ASS expression is relatively high in retinoblastoma cells, ADIinduced arginine deprivation inhibits proliferation and induces cell death (Fig. 3). This could be due to the lack of ASS activity in retinoblastoma cells. To evaluate both anti-tumor activity of ADI and ASS activity in retinoblastoma cells, we examined LDH release i) in the control medium with or without $\mathrm{ADI}$, and ii) in the control medium with ADI or L-arg- free medium without ADI. With the treatment of ADI, LDH release was significantly increased in retinoblastoma cells, especially in SNUOT-Rb1 cells, but slightly increased in MCF-7 cells (Fig. 4), where ASS is highly expressed similarly to retinoblastoma cells (Fig. 2A). The amount of $\mathrm{LDH}$ release by arginine deprivation from culture media was similar to that of ADI-induced arginine deprivation. These data suggest that ADI-induced retinoblastoma cell death could result from arginine deprivation, as retinoblastoma cells lack ASS activity even at high expression of ASS.

\section{Discussion}

Retinoblastoma is the most common malignant tumor of the retina and usually occurs in children below 4 years of age. It is an aggressive tumor that can lead to loss of vision and the eye, and in extreme cases, to death. Treatment methods depend on the stage of the disease, which can include surgical enucleation of the afflicted eye, local therapy (episcleral brachytherapy, cryotherapy, laser photocoagulation, or transpupillary thermotherapy), chemotherapy and/or external beam radiotherapy. To avoid or delay radiation therapy, the use of chemotherapy in conjunction with local therapy for tumor reduction has been investigated. Several agents, including vincristine, cyclophosphamide, doxorubicin, epipodophyllotoxins, and platinum-based products, have proven effective in metastatic retinoblastoma $(3,19-24)$, however, with the increasing incidence of the systemic toxicity, in particular, epipodophyllotoxin-related leukemias (25), new chemotherapy protocols should be developed.

In the present study, we investigated whether the arginine deprivation by ADI treatment could be another treatment option for retinoblastoma. Amino acid deprivation therapy has been encouraged in the field of cancer treatment, because amino acid deprivation cannot introduce toxins, but can induce physiological and metabolic imbalances (26). Of the 20 or so amino acids that could be manipulated, arginine was the first to be seriously explored, but methionine, tryptophan, phenylalanine, and other amino acids have had their champions (27). Because, arginine is a semi-essential amino 
A

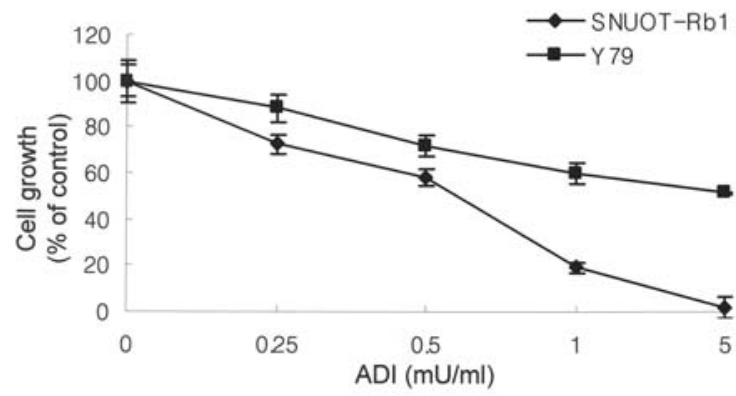

B

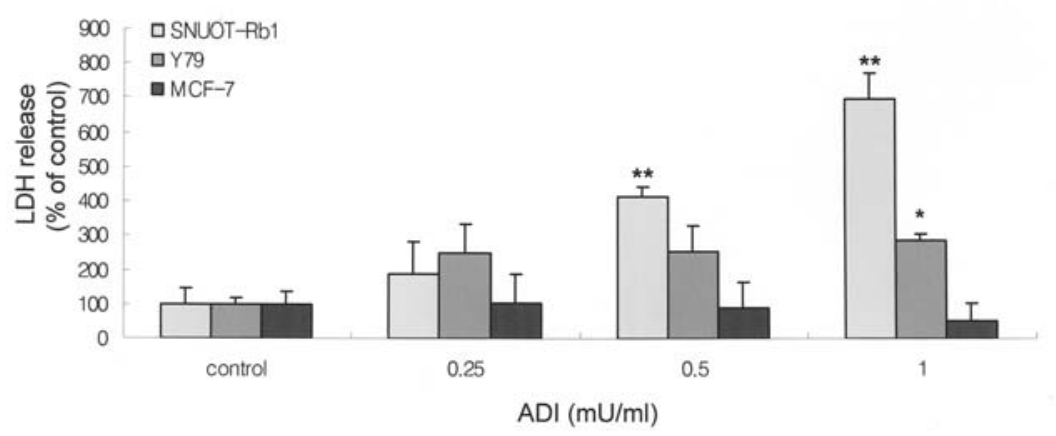

Figure 3. Effect of ADI on the growth and viability of retinoblastoma cells. Cells were seeded in arginine containing medium and then treated with increasing concentrations of ADI $(0.25-5 \mathrm{mU} / \mathrm{ml})$ for $72 \mathrm{~h}$. (A) Cells were stained with trypan blue and counted with a haemocytometer. (B) LDH release in cell culture media was measured. The data shown are the means of triplicate cultures of each cell and are presented as a percentage of control cells that received medium only. ${ }^{*} \mathrm{P}<0.005 .{ }^{*} \mathrm{P}<0.0005$.

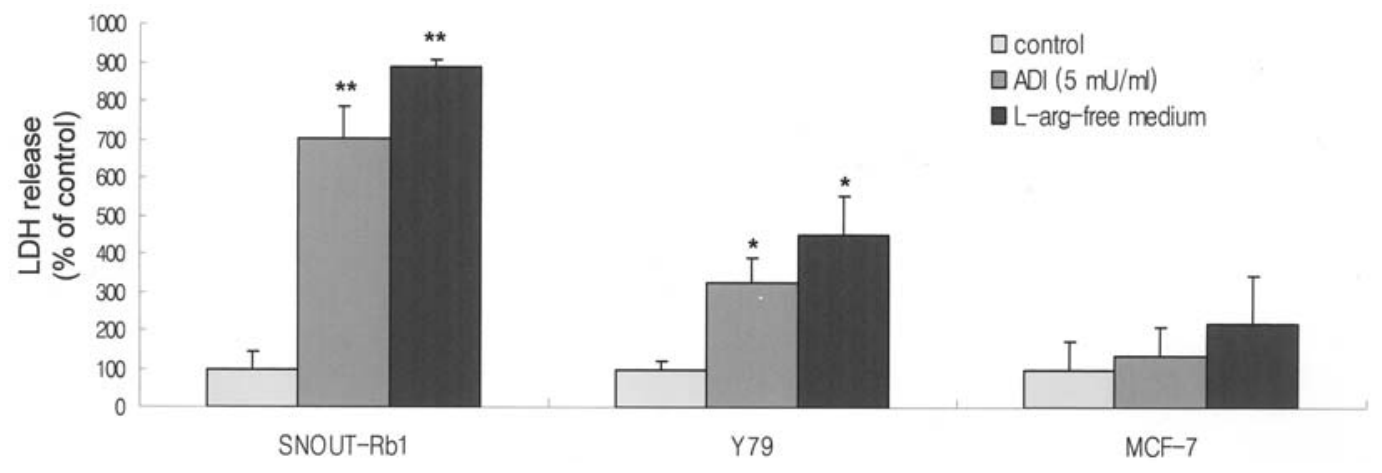

Figure 4. The effect of arginine-free media on retinoblastoma cells. Cells were cultured in complete medium (as $100 \%$ ), $5 \mathrm{mU} / \mathrm{ml}$ ADI containing medium, or L-arg-free medium. After a 3-day incubation, LDH release in cell culture media was measured. The data shown are the means of triplicate cultures of each cell type and are presented as a percentage of control cells that received medium only. ${ }^{*} \mathrm{P}<0.005 .{ }^{* *} \mathrm{P}<0.0005$.

acid to be depleted in normal cell metabolism (10) and is the substrate of numerous enzymes, such as arginase, arginine decarboxylase, and nitric oxide synthase, deprivation of arginine disrupts pleiotypic biochemical responses (28). With the deprivation of arginine, normal fibroblasts can survive in a $\mathrm{G}_{0}$ state $(10,29)$. However, tumor cells keep on dividing into apoptotic cell death (30). Tumor cells seem to be susceptible to arginine deprivation and die rather than arrest within the cell cycle, contrasting with the situation in normal cells.

We previously reported the biochemical characterization of recombinant ADI which originated from $M$. arginini and is expressed in E. coli $(31,32)$, and found out that ADI has a potent anti-tumor activity for solid cancer cells and leukemic cells depending on ASS expression or activity $(15,16,31)$. In the current study, ASS was expressed at a high level in both human retinoblastoma tissues and retinoblastoma cell lines, such as Y79 and SNUOT-Rb1. Retinoblastoma cell death, however, occurred with ADI treatment, which was similar to that of arginine deprivation from culture media (L-arg-free medium). These results indicate that ADI-induced retinoblastoma cell death could result from arginine deprivation, as retinoblastoma cells lack ASS activity even at high expression of ASS.

All these findings led us to conclude that arginine deprivation by ADI treatment could be another option of treatment for retinoblastoma due to the low ASS activity in retinoblastoma cells.

\section{Acknowledgements}

We thank Hyoung Oh Jun for technical help with the experiments. This study was supported by a grant from the National R\&D program for cancer control, Ministry of Health \& Welfare, Korea (05-20240-1). 


\section{References}

1. Abramson DH and Schefler AC: Update on retinoblastoma Retina 24: 828-848, 2004.

2. DiCiommo D, Gallie BL and Bremner R: Retinoblastoma: the disease, gene and protein provide critical leads to understand cancer. Semin Cancer Biol 10: 255-269, 2000.

3. Beck MN, Balmer A, Dessing C, Pica A and Munier F: First-line chemotherapy with local treatment can prevent external-beam irradiation and enucleation in low-stage intraocular retinoblastoma. J Clin Oncol 18: 2881-2887, 2000.

4. Kim JH, Yu YS, Khwarg SI, Choi HS, Shin HY and Ahn HS Clinical result of prolonged primary chemotherapy in retinoblastoma patients. Korean J Ophthalmol 17: 35-43, 2003.

5. Rodriguez-Galindo C, Wilson MW, Haik BG, Merchant TE, Billups CA, Shah N, Cain A, Langston J, Lipson M, Kun LE and Pratt CB: Treatment of intraocular retinoblastoma with vincristine and carboplatin. J Clin Oncol 21: 2019-2025, 2003.

6. Shields CL, Shields JA and De Potter P: New treatment modalities for retinoblastoma. Curr Opin Ophthalmol 7: 20-26, 1996.

7. Nishimura S, Sato T, Ueda $\mathrm{H}$ and Ueda K: Acute myeloblastic leukemia as a second malignancy in a patient with hereditary retinoblastoma. J Clin Oncol 19: 4182-4183, 2001.

8. Holle LM: Pegaspargase: an alternative? Ann Pharmacother 31: 616-624, 1997 .

9. Yoshioka T, Wada T, Uchida N, Maki H, Yoshida H, Ide N Kasai H, Hojo K, Shono K, Maekawa R, Yagi S, Hoffman RM and Sugita K: Anticancer efficacy in vivo and in vitro, synergy with 5-fluorouracil, and safety of recombinant methioninase. Cancer Res 58: 2583-2587, 1998.

10. Wheatley DN, Scott L, Lamb J and Smith S: Single amino acid (arginine) restriction: growth and death of cultured HeLa and human diploid fibroblasts. Cell Physiol Biochem 10: 37-55, 2000.

11. Takaku H, Takase M, Abe S, Hayashi $\mathrm{H}$ and Miyazaki K: In vivo anti-tumor activity of arginine deiminase purified from Mycoplasma arginini. Int J Cancer 51: 244-249, 1992.

12. Komada Y, Zhang XL, Zhou YW, Ido M and Azuma E: Apoptotic cell death of human T lymphoblastoid cells induced by arginine deiminase. Int J Hematol 65: 129-141, 1997.

13. Gong H, Zolzer F, von Recklinghausen G, Havers W and Schweigerer L: Arginine deiminase inhibits proliferation of human leukemia cells more potently than asparaginase by inducing cell cycle arrest and apoptosis. Leukemia 14: 826-829, 2000.

14. Ensor CM, Holtsberg FW, Bomalaski JS and Clark MA: Pegylated arginine deiminase (ADI-SS PEG20,000 mw) inhibits human melanomas and hepatocellular carcinomas in vitro and in vivo. Cancer Res 62: 5443-5450, 2002.

15. Noh EJ, Kang SW, Shin YJ, Choi SH, Kim CG, Park IS, Wheatley DN and Min BH: Arginine deiminase enhances dexamethasone-induced cytotoxicity in human T-lymphoblastic leukemia CCRF-CEM cells. Int J Cancer 112: 502-508, 2004.

16. Yoon CY, Shim YJ, Kim EH, Lee JH, Won NH, Kim JH, Park IS, Yoon DK and Min BH: Renal cell carcinoma does not express argininosuccinate synthetase and is highly sensitive to arginine deprivation via arginine deiminase. Int J Cancer 120: 897-905, 2006.
17. Morris Jr SM: Enzymes of arginine metabolism. J Nutr 134: 2743S-2767S, 2004

18. Shen LJ, Lin WC, Beloussow K and Shen WC: Resistance to the anti-proliferative activity of recombinant arginine deiminase in cell culture correlates with the endogenous enzyme, argininosuccinate synthetase. Cancer Lett 191: 165-170, 2003.

19. Shields CL, Honavar SG, Meadows AT, Shields JA, Demirci H, Singh A, Friedman DL and Naduvilath TJ: Chemoreduction plus focal therapy for retinoblastoma: Factors predictive of need for treatment with external beam radiotherapy or enucleation. Am J Ophthalmol 133: 657-664, 2002.

20. Greenwald MJ and Strauss LC: Treatment of intraocular retinoblastoma with carboplatin and etoposide chemotherapy. Ophthalmology 103: 1989-1997, 1996.

21. Levy C, Doz F, Quintana E, Pacquement H, Michon J, Schlienger P, Validire P, Asselain B, Desjardins L and Zucker JM: Role of chemotherapy alone or in combination with hyperthermia in the primary treatment of intraocular retinoblastoma: Preliminary results. Br J Ophthalmol 82: 1154-1158, 1998.

22. Friedman DL, Himelstein B, Shields CL, Shields JA, Needle M, Miller D, Bunin GR and Meadows AT: Chemoreduction and local ophthalmic therapy for intraocular retinoblastoma. J Clin Oncol 18: 12-17, 2000.

23. Gallie BL, Budning A, DeBoer G, Thiessen JJ, Koren G, Verjee Z, Ling V and Chan HS: Chemotherapy with focal therapy can cure intraocular retinoblastoma without radiotherapy. Arch Ophthalmol 114: 1321-1328, 1996.

24. Kingston JE, Hungerford JL, Madreperla SA and Plowman PN Results of combined chemotherapy and radiotherapy for advanced intraocular retinoblastoma. Arch Ophthalmol 114: $1339-1343,1996$.

25. Smith MA, Rubinstein L and Ungerleider RS: Therapy-related acute myeloid leukemia following treatment with epipodophyllotoxins: Estimating the risks. Med Pediatr Oncol 23: 86-98, 1994.

26. Milner JA: Metabolic aberrations associated with arginine deficiency. J Nutr 115: 516-523, 1985.

27. Wheatley DN: Controlling cancer by restricting arginine availability-arginine-catabolizing enzymes as anticancer agents. Anticancer Drugs 15: 825-833, 2004.

28. Rabinovitz M: The pleiotypic response to amino acid deprivation is the result of interactions between components of the glycolysis and protein synthesis pathways. FEBS Lett 302: 113-116, 1992.

29. Lamb J and Wheatley DN: Single amino acid (arginine) deprivation induces G1 arrest associated with inhibition of cdk4 expression in cultured human diploid fibroblasts. Exp Cell Res 255: 238-249, 2000

30. Scott L, Lamb J, Smith S and Wheatley DN: Single amino acid (arginine) deprivation: rapid and selective death of cultured transformed and malignant cells. Br J Cancer 83: 800-810, 2000.

31. Kang SW, Kang H, Park IS, Choi SH, Shin KH, Chun YS, Chun BG and Min BH: Cytoprotective effect of arginine deiminase on taxol-induced apoptosis in DU145 human prostate cancer cells. Mol Cell 10: 331-337, 2000.

32. Noh EJ, Kang SW, Shin YJ, Kim DC, Park IS, Kim MY, Chun BG and Min BH: Characterization of mycoplasma arginine deiminase expressed in E. coli and its inhibitory regulation of nitric oxide synthesis. Mol Cell 13: 137-143, 2002 . 